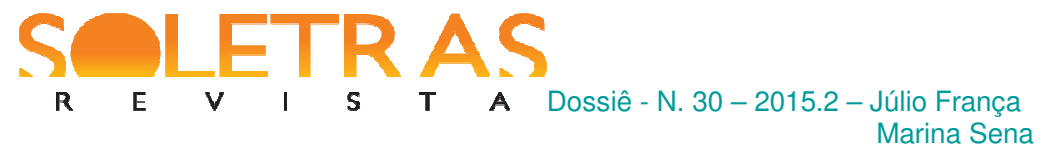

\title{
O Gótico-Naturalismo em Rodolfo Teófilo
}

\author{
Júlio França ${ }^{1}$ \\ Universidade do Estado do Rio de Janeiro
}

Marina Sena ${ }^{2}$

Mestranda pela Universidade do Estado do Rio de Janeiro

Resumo: Reconhecido por ser o mestre do Naturalismo no Ceará, Rodolfo Teófilo (18631932) retratou, em suas obras ficcionais, a seca e a fome no Nordeste durante o século XIX. Boa parte de suas narrativas são ambientadas no sertão devastado pelas secas - sobretudo aquelas ocorridas em 1877 e 1879 -, dando forma a espaços ficcionais atrozes, miseráveis e ermos. Suas personagens, inseridas em tal espaço, configuram-se como indivíduos que vivenciam os horrores da fome, e por elas são gradativamente transformados em criaturas animalizadas e instintivas, que progressivamente perdem seus atributos humanos. Seu estilo de prosa é contaminado pela forte orientação cientificista que caracterizava a escola da qual fazia parte, fazendo com que descrevesse as cenas mórbidas e de teor sexual com riqueza de detalhes. Por conta disso, o escritor foi acusado pela crítica da época, e pela historiografia novecentista, de ter construído "descrições excessivas" e de ter cometido exageros narrativos. O presente artigo propõe uma leitura de seu romance Os Brilhantes (1895), de modo a demonstrar como os supostos desvios ou exageros de Teófilo em relação ao Naturalismo estariam relacionados à tradição da literatura gótica. Nossa hipótese de trabalho é a de que há, no discurso ficcional do autor, uma confluência entre ambas as poéticas - a gótica e a naturalista.

Palavras-chave: Naturalismo. Gótico. Rodolfo Teófilo.

\section{Rodolfo Teófilo, o excessivo}

A historiografia literária brasileira tornou um truísmo a afirmação de que todo escritor comprometido com a estética naturalista intencionava descrever - com a maior fidelidade possível em relação ao mundo real e com a precisão de um relatório científico - o espaço narrativo, o caráter das personagens e as ações (VERÍSSIMO, 1998; SODRÉ, 1965; CANDIDO, 1999). Esse era, ao menos, o modo como a crítica hegemônica compreendeu o projeto do Naturalismo, como bem descreve Flora Süssekind em seu livro Tal Brasil, qual romance?:

\footnotetext{
${ }^{1}$ Doutor em Literatura Comparada pela UFF (2006), com pós-doutorado pela Brown University (2014-2015). É Professor de Teoria da Literatura do Instituto de Letras e do Programa de Pós-graduação em Letras da UERJ. É líder do Grupo de Pesquisa Estudos do Gótico (CNPq) e integrante do GT da ANPOLL "Vertentes do Insólito Ficcional". Seus artigos e ensaios podem ser encontrados no site "Sobre o Medo" (sobreomedo.wordpress.com).

${ }^{2}$ Bacharel em Letras (Português-Literaturas) e mestranda em Teoria da Literatura pela Universidade do Estado do Rio de Janeiro. É integrante do Grupo de Pesquisa Estudos do Gótico (CNPq).
} 
O que se lia como ficção, se dizia também ciência. Ler $O$ homem equivalia a um estudo sobre os sintomas histéricos. Assim como ler $O$ cortiço, segundo a crítica da época, talvez fosse o mesmo que "ver" um cortiço. O que se representava como ficção se apresentava também como documento (SÜSSEKIND, 1984, p. 65).

Alfredo Bosi encarou essa pretensão ao documental de modo similar: "O Realismo se tingirá de Naturalismo, no romance e no conto, sempre que fizer personagens e enredos submeterem-se ao destino cego das 'leis naturais' que a ciência da época julgava ter codificado (...)" (BOSI, 2006, p. 168. Grifo nosso). Porém, mesmo reconhecendo a interferência dos discursos científicos nos romances naturalistas, Bosi aponta que há "um resíduo romântico nesse vezo de perscrutar o excepcional, o feio, o grotesco" (BOSI, 2006, p. 171). Na sequência de seu raciocínio, o crítico ainda afirma que: "[a] pretensa neutralidade [dos romances naturalistas] não chega a ponto de ocultar o fato de que o autor carrega sempre de tons sombrios o destino das suas criaturas" (BOSI, 2006, p. 172. Grifo nosso).

Os "tons sombrios" de que fala Bosi podem ser um ponto de partida para entender o Naturalismo brasileiro, em fins do século XIX, como uma forma de expressão artística que se caracterizaria por descrever, com minúcia de detalhes, personagens e atos extremos, e que tematizaria questões ligadas a comportamentos limítrofes do ser humano: loucura, assassínio, sexo e perversidade.

Tal modo de representação da realidade, dito sombrio ou exagerado, encontrou resistência em boa parte da historiografia literária brasileira. Alguns pesquisadores apontaram como defeitos esses excessos de nossa literatura naturalista. Tome-se, como exemplo, o seguinte comentário de Afrânio Coutinho e Sônia Brayner, no prefácio à edição de 1972 do romance Os Brilhantes (1895), de Rodolfo Teófilo:

É, sobretudo, nos livros [naturalistas] secundários que melhor se apreende a técnica e as ideias da escola. E nestes livros o que ressalta mais frequentemente são os defeitos resultantes das exageradas preocupações com os ditames da escola: a mania cientificista (...) o fatalismo e determinismo biológicos, (...) o exagero do fatualismo e da mecanização, a brutalidade do realismo na descrição de certas cenas, a linguagem crua, (...) o gosto da minúcia nas descrições (COUTINHO; BRAYNER, 1972, p. 7. Grifo nosso).

Estabelecendo limites ideais e arbitrários para o quão descritivo e o quão científico um romance naturalista deve ser, comentários como o de Coutinho e Brayner multiplicaram-se tanto em nossa crítica oitocentista como em nossa historiografia novecentista. A afirmação de que os escritores naturalistas possuíam uma "exagerada preocupação com os ditames da 


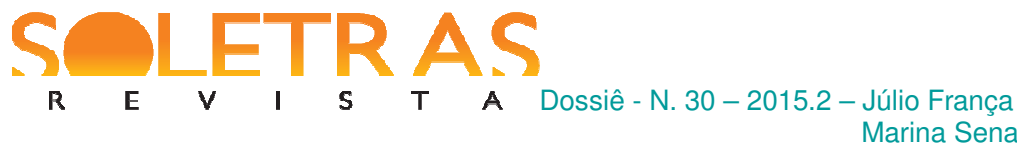

escola" correspondia dizer que eles perdiam em qualidade artística ao se preocuparem em demasia com o discurso cientificista, as justificativas deterministas e as minúcias descritivas.

Já em finais do século XIX, havia sido construído um ideal de Naturalismo em nossos estudos literários. A pedra de toque do romance brasileiro naturalista era a prosa de Émile Zola (DUARTE, 1881; ROMERO, 1882; CARVALHO, 1887; CAMINHA, 1895), e qualquer romance que fosse mais ou menos científico e descritivo do que um romance do mestre francês era considerado má obra. ${ }^{3}$ Um exemplo pode ser observado na fortuna crítica sobre a obra do escritor naturalista Rodolfo Teófilo, baiano por nascimento e cearense por criação, que ficou conhecido por suas impactantes narrativas que tematizam, essencialmente, a seca no Nordeste durante o século XIX. Teófilo foi duramente criticado pelas imagens violentas e detalhadas de seu romance A Fome (1890). Lúcia Miguel Pereira (1988), por exemplo, ao analisar as cenas descritivas da seca e da fome no romance, diz: "Sem dúvida, nenhum outro naturalista chegou a tais excessos delirantes". A ensaísta considera ainda que a "preocupação científica" do Naturalismo "representou um pesado fator antiartístico" (PEREIRA, 1988, p. 135). ${ }^{4}$ Dessa forma, Pereira parece sugerir que as descrições excessivas provinham do desejo de retratar os fatos de modo documental, em prejuízo da realização artística. Como bem observa Leonardo Mendes (2014, p. 34-35), o ponto de vista da ensaísta supõe que "ciência e arte eram domínios excludentes”, o que justificaria assim o juízo de valor negativo.

Já à época de publicação de suas obras, Teófilo recebera duras críticas por seu estilo de cartorário (MENDES, 2014), como ilustra aqui a censura de José Veríssimo à falta de ornamentação e aos jargões técnicos que caracterizavam a linguagem do romancista:

Os processos descritivos do autor, principalmente quando quer referir estado d'alma, têm a secura e o descolorido de um inventário ou de um corpo de delito. Cometendo um erro grave de ofício, o autor, como já notei, multiplica a terminologia da técnica médica e psicológica (VERÍSSIMO, 1901, p. 266).

Adolfo Caminha, companheiro de escola naturalista, também desaprova o romancista do Ceará, vendo em seu cientificismo pouco além de uma ostentação vulgar de conhecimento: “(...) o Sr. Teófilo ama as exibições e deseja também um lugar entre os ilustrados da terra,

\footnotetext{
${ }^{3}$ No Brasil, os estudos literários sobre Naturalismo podem ser divididos, essencialmente, em dois momentos (cf. PRADO, 2005). O primeiro é o da crítica oitocentista, que tomava como padrão estético a prosa de Zola e produzia juízos críticos sempre em comparação com a obra do escritor francês. O segundo momento é o da historiografia literária novecentista, mais interessada em identificar, nas obras brasileiras, traços naturalistas característicos, traçando assim um retrato do que teria sido tal movimento literário em nosso país.

${ }^{4}$ Lúcia Miguel Pereira comenta que o "desejo [de Teófilo] de exibir conhecimentos científicos lhe tornou o estilo, já de si empedrado e baço, comicamente desajeitado para a ficção, e privou as suas personagens da fraca vitalidade que possuíam" (PEREIRA, 1988, p. 133). Seria essa intenção de utilizar ostensivamente, em seus contos e romances, um conhecimento da ciência da época que faria de Rodolfo Teófilo um autor excessivamente científico.
} 


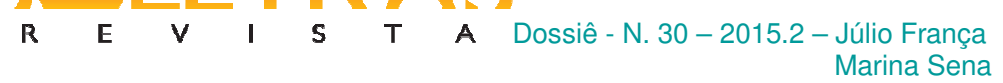

supondo, talvez, que o romance moderno de observação e análise presta-se a digressões científicas de qualquer natureza" (CAMINHA, 1895, p. 144). Para Caminha, as descrições de Teófilo são similares às que se encontram "nos compêndios de fisiologia", e por isso sentencia: "Se a sua vocação [de Teófilo] é a ciência pura, valia mais a pena enriquecer a bibliografia nacional com obras de ciência" (CAMINHA, 1895, p. 145).

É notável como os comentários de Veríssimo e Caminha aproximam-se pelo mesmo tipo de crítica: Teófilo era científico demais e, nesse sentido, afastar-se-ia do ideal de romance experimental a ser seguido, proposto por Zola. Desde então, Teófilo criou uma má fama por ser um escritor por demais cientificista e, entre todos os naturalistas de seu tempo, o mais excessivo. Ao ser documental e científico em demasia, Teófilo seria um mau naturalista, e, por extensão, um mau escritor.

Note-se que os comentários dos historiógrafos e críticos supracitados não condenam Teófilo por se desviar da poética naturalista, mas justamente por lhe seguir os preceitos à risca, demasiadamente. Isso se torna evidente nas restrições que se fazem a, pelo menos, cinco aspectos de seu estilo: a) à exploração de comportamentos limítrofes do ser humano; b) ao detalhamento com que narra ações de perversidade e de transgressão moral; c) à brutalidade com a qual são descritas as cenas de violência; d) ao emprego recorrente de termos científicos; e e) à ostensiva pretensão documental do autor. Em conjunto, tais características dariam forma à estética do excesso que se atribui ao romancista. Nossa hipótese é a de que tais excessos possam ser entendidos por uma outra perspectiva, em diálogo com a tradição da literatura gótica, e não simplesmente como consequência direta de uma maior ou menor obediência às normas naturalistas.

A estética do excesso em Teófilo pode estar relacionada a uma perspectiva desiludida com a modernidade e desacreditada no ser humano, adequada ao retrato do Sertão que pretendeu construir em sua obra. A esta perspectiva chamamos visão de mundo gótica, que era comum não só aos escritores naturalistas da época, mas a escritores finisseculares como um todo. Maurício Menon foi um dos que reconheceu - sem negar a influência das teorias do determinismo no modo como Teófilo retrata as personagens monstruosas que vivenciam a seca - que "os substantivos escolhidos por Teófilo (...) apontam para a monstruosidade; já os adjetivos, visivelmente, têm por objetivo suscitar o horror em quem lê" (MENON, 2007, p. 156). A produção do horror como efeito estético de recepção parece estar relacionada diretamente com "os excessos delirantes" que Pereira critica. 
Nosso objetivo neste artigo é, a partir da análise da construção das imagens da seca e da fome no romance Os Brilhantes, demonstrar como a dualidade entre as poéticas naturalista e gótica concretiza-se na ficção de Rodolfo Teófilo, dando forma ao que a crítica e a historiografia literárias brasileiras identificaram, de modo pejorativo, como uma estética do excesso.

\section{A poética do desencanto}

A influência do Gótico na literatura brasileira tem sido estudada por diversos pesquisadores contemporâneos, que vêm demonstrando, com sucesso, como os traços góticos são muito mais frequentes e disseminados na literatura brasileira do que a crítica e a historiografia tradicionais nos fizeram acreditar. Sandra Vasconcelos (2012) e Daniel Sá (2010) têm explorado a presença de tal influência no Romantismo, enquanto Alexander Meireles (2013) e Fernando de Barros (2014) demonstram que tal influxo estende-se, pelo menos, até meados do século XX. Mesmo o Naturalismo não escapou de sua influência, como os trabalhos de Maurício Menon (2007) e Leonardo Mendes (2004) indicam.

A afirmação de que o Gótico influenciou a literatura brasileira de cunho realista soa, em um primeiro momento, como um paradoxo. O aparente contrassenso justifica-se, quando se limita a literatura gótica a suas formas e fórmulas setecentistas, com seus espaços narrativos medievos e sua exploração contumaz de eventos de cunho sobrenatural. Para se entender o que chamamos de influência gótica na literatura brasileira e, neste caso específico, no Naturalismo, é necessário explicitar, pois, a noção de gótico com a qual trabalhamos.

Dada a notável flexibilidade do termo, parece impossível chegar a uma definição única do que seja Gótico, já que a sua própria história demonstra uma capacidade de adaptação do conceito aos mais amplos usos. Por tal razão, partindo das reflexões de David Stevens (2000), propomos compreender o Gótico menos como o estilo de época que teve seu auge na segunda metade do século XVIII e início do XIX, e mais como uma tradição literária que tem persistido nos últimos 250 anos. Tal tradição seria a confluência entre uma linguagem artística altamente estetizada, convencional e repleta de simbolismos, e uma visão de mundo bastante desencantada com a sociedade moderna.

A visão de mundo gótica afetou profundamente a maneira como a arte é pensada e expressada na modernidade. Caracterizar-se-ia por não se revelar entusiasta do progresso científico e do futuro; por não acreditar na suposta bondade natural do ser humano, tampouco 
na redenção divina; por não ter como pressuposto estético os padrões de beleza, harmonia e perfeição - por apresentar, em suma, uma compreensão sombria, negativa e desacreditada do mundo.

Essa visão de mundo tomou forma artística em uma literatura que se caracteriza por um conjunto de aspectos recorrentes (STEVENS, 2000; FRANÇA, 2015): (i) a construção de espaços narrativos, exóticos ou familiares, que são descritos como loci horribiles; (ii) a relação fantasmagórica com o passado, que ressurge para assombrar o presente; (iii) a caracterização de personagens como monstruosidades, por conta da própria natureza humana ou de psicopatologias; (iv) o desenvolvimento de enredos que exploram, tanto no plano da diegese quanto no da recepção, efeitos melodramáticos e emocionais; (v) a utilização contínua de campos semânticos relacionados à morte, à morbidez e à degeneração física e mental; vi) a produção do medo como efeito estético; vii) o aprofundamento na psicologia das personagens, sobretudo no que concerne a questões relacionadas à sexualidade; viii) a estratégia narrativa da "moldura", com a exploração labiríntica de tramas dentro de tramas.

O conceito de Gótico com o qual trabalhamos, portanto, abrange tanto sua primeira realização histórica, em meados do século XVIII, quanto suas manifestações posteriores - ao longo do século XIX, no fin-de-siècle oitocentista, no modernismo norte-americano de William Faulkner e Flannery O'Connor e, como pretendemos demonstrar, na dispersão de seus elementos na literatura brasileira naturalista.

\section{O desencanto científico}

Gótico e Naturalismo não são frutos de causas similares: enquanto o primeiro possui um forte desencanto com a modernidade e uma profunda desconfiança em relação ao discurso da razão - seja ele iluminista ou positivista -, o segundo baseia os seus fundamentos estéticos em pressupostos científicos e tenciona elaborar, em ficção, um documento da realidade.

Por conta de tal intenção cientificista, encontramos alguns topoi frequentes na literatura naturalista: a presença de um médico como autoridade moral ou intelectual (SÜSSEKIND, 1984); a temática da histeria feminina baseada nas ideias de Jean-Martin Charcot (18251893); o meio e a hereditariedade como elementos formadores de caráter, a partir das ideias de Hippolyte Taine (1828-1893); a tendência atávica do criminoso para o mal, baseando-se na teoria de Cesare Lombroso (1835-1909) - apenas para citar alguns aspectos dessa literatura que se apoiavam no discurso científico da época. 
R E V I S T A Dossiê- N. 30-2015.2- Júlio França

Marina Sena

O escritor naturalista, no entanto, não endossava cegamente a razão científica. Mesmo apoiados em diversas dessas teorias científicas, os naturalistas frequentemente tematizavam em suas obras o lado sombrio gerado por essa mesma ciência da época. Por trás da suposta neutralidade de seus narradores, nota-se a inquietude resultante de uma percepção sombria da realidade, alimentada pela dúvida quanto ao progresso positivista ser capaz de redimir uma tão brutalizada humanidade.

O escritor naturalista, talvez possamos dizer, sofria dos males do excesso de conhecimento. Quanto mais se entendia o homem, mais se desenvolvia o mal-estar relacionado à percepção de que a ciência - ainda que responsável por indiscutíveis melhorias nas condições de vida da humanidade - não dava conta da complexidade dos desafios das sociedades humanas.

Paradoxalmente, serão as luzes do conhecimento as responsáveis por projetar, nas narrativas, as sombras que aproximarão o Naturalismo, em fins do XIX, da estética gótica, dando forma a uma nova poética: o Gótico-Naturalismo. Nas palavras de Charles Crow:

Gótico-Naturalismo, à primeira vista, parece um oxímoro, uma óbvia impossibilidade: o Naturalismo é, em sua definição mais comum, baseado numa visão de mundo científica, em pensadores como Taine, [Claude] Bernard e Herbert Spencer. Um romance naturalista é um relatório laboratorial, com uma perspectiva inflexível do mundo material; não há nele, obviamente, lugar para as sombras e paixões góticas. Ainda que o Naturalismo raramente seja o livro de casos distanciado e objetivo que pretendia ser, um dos seus traços assinados parece ser a facilidade com que combina, em sua hibridez, outras formas: o melodrama doméstico, a fábula moral, a história de aventura infantil - e o Gótico (CROW, 1994, p. 123. Tradução nossa).

A percepção de Crow sobre a obra de Zola é especialmente interessante. O crítico demonstra que, mesmo nos romances do grande mestre da tradição naturalista, há diversas passagens góticas, como o retorno constante do cadáver flutuante de Chaval para o seu assassino. O escritor naturalista teria, portanto, encontrado na tradição gótica os modos de expressão adequados para comunicar uma visão de mundo desiludida.

Nas obras gótico-naturalistas, a narrativa literária tende a funcionar menos conforme os ditames do romance experimental - espelhar a realidade por meio de um discurso mimético, neutro e científico - e mais como uma representação dos medos gerados pela percepção, sob uma ótica científica, dessa mesma realidade. Serão comuns a presença de personagens monstruosas por conta de psicopatologias hereditárias ou de uma tendência atávica para o mal - ressoando as ideias de Lombroso; personagens monstruosas femininas justificadas pelas ideias de histeria de Charcot; a construção de loci horribiles que 
determinam o caráter das personagens, ecoando o determinismo de Taine; personagens famélicas que perdem sua humanidade até se converterem em animais, numa distorção da teoria evolucionista de Darwin; e uma escolha vocabular que mescla a linguagem tétrica e altamente estetizada do Gótico com o jargão científico - não raramente hermético e alambicado.

A utilização da estética gótica é bastante evidente quando, por exemplo, o autor descreve casos de patologias mentais que quase sempre desencadeiam algum tipo de ato monstruoso por parte da personagem afetada - seja ela um faminto, um criminoso ou uma histérica. Ao justificar racionalmente os atos monstruosos, descrevendo-os ou como consequências da fisiologia humana, ou como resultados da influência do meio e do momento histórico, naturalizam-se as causas e os efeitos dos desvios morais. Nesse sentido, Gótico e Naturalismo muito se aproximam, também, no que diz respeito às suas visões de mundo.

Com o objetivo de demonstrar os elementos do Gótico-Naturalismo na literatura brasileira tomaremos, como objeto de análise, o romance Os Brilhantes, de Rodolfo Teófilo, focalizando três aspectos fundamentais: (a) a construção de espaços narrativos exóticos que são descritos como loci horribiles; (b) a utilização contínua de campos semânticos relacionados à morte, à morbidade e à degeneração física e mental; e (c) a ciência utilizada, no discurso ficcional, com a finalidade de causar horror como efeito estético de recepção.

\section{Ecos góticos, delírios naturalistas}

Os Brilhantes é um romance histórico, publicado em 1895, que tematiza a vida de Jesuíno Brilhante, cangaceiro que viveu no interior do Nordeste durante o século XIX. O romance narra, essencialmente, a disputa existente entre o seu grupo de cangaço, os Brilhantes, e os seus adversários, os Calangros, no período compreendido entre 1874 e 1882.

Jesuíno Brilhante vem de uma família de criadores de gado, dona de grandes extensões de terra. Ele é conhecido na região por seu caráter bondoso e temperamento tranquilo, até o momento em que testemunha o assassinato de seu primo pelos Calangros. A natureza pacífica da personagem dá lugar a um temperamento frio e calculista. A perseguição aos assassinos por vingança faz com que o protagonista crie o seu próprio grupo de cangaceiros.

Para os fins deste artigo, será abordado apenas o episódio de Os Brilhantes que tem como espaço-tempo narrativo a seca ocorrida em 1877. Conhecida por ter sido uma das piores secas ocorridas no Nordeste durante o século XIX, a seca de 1877 foi inesperada e dizimou 


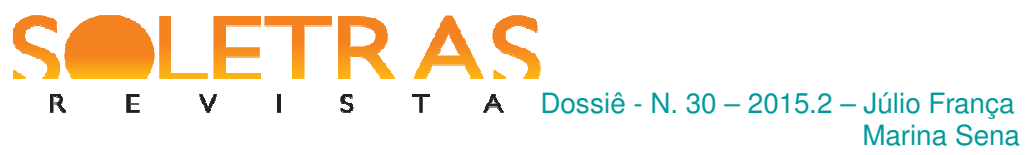

cerca de 500 mil sertanejos que não puderam migrar para Fortaleza, apesar de todos os esforços (CAMPOS; STUDART, 2001).

O tema da seca não era estranho a Teófilo. Seu primeiro romance, A Fome, de 1890, também é ambientado durante a seca de 1877. Nas palavras de Mauricio Menon (2007, p. 138), nessa obra os retirantes são descritos como "zumbis perambulantes, gerados nas oficinas da miséria e da fome”. Esse tipo de descrição fez com que Teófilo fosse acusado por seus já mencionados exageros narrativos (PEREIRA, 1988) e também por ter utilizado uma linguagem científica demais para uma obra de ficção (VERÍSSIMO, 1901; CAMINHA, 1895).

Mas qual relação haveria entre os exageros narrativos de que fala Pereira e as digressões científicas de que fala Caminha? Supomos, a princípio, que essas duas características estão relacionadas. Quando a transformação no caráter de Jesuíno Brilhante efetua-se, o narrador a descreve como uma modificação biológica:

O sangue da vítima havia-lhe borrifado o rosto, e a fisionomia do Brilhante foi pouco a pouco perdendo a expressão de assombramento, para se carregar de uma ferocidade que metia medo. Aquele semblante plácido de outrora era crispado agora pelas fundas linhas do ódio.

Uma mudança radical havia se operado naquela criatura. Portador $d a$ nevrose do homicídio, herdada de um de seus ascendentes maternos, mas até então em estado latente, Jesuíno teria talvez logrado viver sem matar, se não tivesse sido testemunha do assassinato de seu parente.

A nevrose explodiu com violência. Ao período de atordoamento, no qual parecia por completo suspensa no Brilhante a intelecção, a essa crise de adormecimento de suas qualidades psíquicas, sucedeu um acesso de loucura, cujo furor via-se-lhe estampado no semblante.

Com o olhar cintilante e desvairado, um olhar que feria, com os músculos do rosto em uma dança constante, Jesuíno se achegou ao morto e molhando o dedo indicador no sangue, muito vivo e muito rubro, que ensopava o cadáver, fez uma cruz na coronha do seu bacamarte (TEÓFILO, 1972, p. 767. Grifos nossos).

O grande desencadeador do novo caráter de Jesuíno é o sangue borrifado no rosto da personagem, que desperta uma latente tendência hereditária: a nevrose do homicídio. $\mathrm{O}$ estabelecimento dessa relação causal revela a forte influência da teoria do médico e filósofo Cesare Lombroso, para quem o criminoso seria

(...) geneticamente determinado para o mal, por razões congênitas. Ele traz no seu âmago a reminiscência de comportamento adquirido. É uma tendência inata para o crime. Pelas ideias de Lombroso (...) o criminoso não é totalmente vítima das circunstâncias sociais e educacionais desfavoráveis, mas sofre pela tendência atávica, hereditária para o mal (ROQUE, 2010, p. 7).




Expressões como "nevrose", "herdada de (...) ascendentes maternos", "estado latente" e "crise de adormecimento de suas qualidades psíquicas" (TEÓFILO, 1972, p. 76) revelam a preocupação do autor em explicar por meio do vocabulário científico e médico da época o caráter das personagens. É esse tipo de descrição que justificaria, a princípio, as acusações de José Veríssimo e a sugestão sarcástica de Adolfo Caminha (1895, p. 145): "Por que não escreve o autor da Fome tratados de fisiologia e de ciências naturais?".

Na narração dos episódios da seca, sobretudo na descrição dos retirantes, a conjunção entre a abordagem científica e a ênfase nos aspectos tétricos é potencializada, como na sequência abaixo, em que os sertanejos, atingidos pela fome, alimentam-se de qualquer animal encontrado:

Tendo sido consumidos todos os animais de carne mais saborosa e, sem outro recurso, passaram a se alimentar de raposas, cassacos, cobras e lagartos. Comiam com apetite a carne do fedorento marsupial e do réptil, branca e macia, com espinhas curvas e pontudas.

A miséria não admite repugnâncias e por isso, eles mastigavam o espinhaço de uma cobra chupando-lhe o tutano com a satisfação com que comeriam o mais saboroso peixe. [...] Os gastos excediam os lucros e daí um notável desequilíbrio na saúde do corpo. A magreza, como consequência da insuficiência da comida, lhes escaveirava o rosto, tornando a figura repelente (TEÓFILO, 1972, p. 248). (Grifos nossos).

As consequências fisiológicas da fome sobre o sertanejo desdobram-se em múltiplas faces. Por um lado, a morbidez física é dita "repelente", em virtude das faces escaveiradas. Por outro lado, o drama da seca degenera psicológica e moralmente o retirante, que tem sua identidade degradada.

Em Os Brilhantes, o meio hostil gera indivíduos igualmente hostis. Teófilo apoia-se na teoria determinista do historiador Hippolyte Taine, que postulava que o homem era determinado por três fatores: a raça, o meio e o momento histórico. A teoria de Taine era, de fato, muito cara aos naturalistas, tanto os brasileiros quanto os franceses, que construíram boa parte de suas personagens partindo desse pressuposto. Como já ressaltou Nelson Sodré, tratava-se de "uma das peças fundamentais da ficção naturalista, o meio, herdado dos ensinamentos de Taine. Misturado com a hereditariedade, constituía, sistematicamente, a fórmula verídica, o segredo da realidade" (SODRÉ, 1965, p. 22).

A seca, neste romance, não pode ser compreendida apenas como um fenômeno climático cíclico. Ela modificaria de modo tão profundo a paisagem geológica, natural e social do espaço que o Sertão, outrora habitável, por influência dela converteria as 


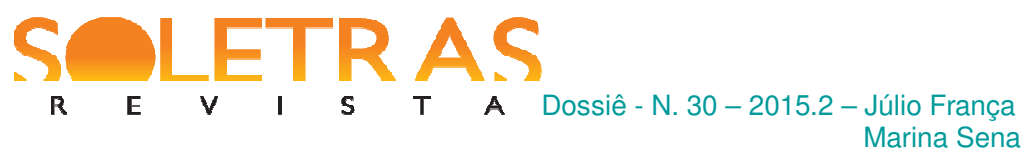

personagens em monstruosidades. Como aponta Ozíris Borges Filho, em seu Introdução à topoanálise: "[m]uitas vezes, o espaço influencia a personagem a agir de determinada maneira. Os exemplos mais claros dessa relação poderão ser encontrados, na literatura brasileira, nos romances naturalistas" (BORGES FILHO, 2007, p. 37). Nesse sentido, a Seca é o agente catalisador da transformação do sertão em um locus horribilis composto, por um lado, pela paisagem geológica agreste e, por outro, pela paisagem humana monstruosa.

Como aponta Yi-Fu Tuan, em seu livro Paisagens do medo:

Pense agora nas forças hostis. Algumas delas, como a doença e a seca, não podem ser percebidas diretamente a olho nu. A paisagem de doença é uma paisagem das consequências terríveis da doença: membros deformados, cadáveres, hospitais e cemitérios cheios e os incansáveis esforços das autoridades para combater uma epidemia (...). A seca é a ausência de chuva, também um fenômeno invisível, exceto indiretamente pela devastação que produz: safra murcha, animais mortos e moribundos, pessoas mortas, desnutridas e em estado de pânico (TUAN, 2005, p. 13).

A relação metonímica entre personagem e espaço é um recurso utilizado largamente por Teófilo para caracterizar esse locus horribilis. Durante a seca, o sertão e o sertanejo fundemse para compor o mesmo mórbido cenário. Destacamos, a seguir, o episódio em que um de cangaceiros de Jesuíno Brilhante, Silvestre, caminha pela serra do Cajueiro:

A serra do Cajueiro se comparava bem a uma úlcera mal cicatrizada, coberta de crosta sã, tendo sobre ela pontos podres onde fazia pasto a gangrena. Silvestre não se apercebia disso. Caminhava pensando na terminação do flagelo, alegre talvez de voltar à casa, quando na proximidade de um desfiladeiro, lugar ermo e muito esquisito começou a lhe impressionar mal um cheiro de chaga, de couro ardido. Parou e resfolegou brandamente, procurando sorver todas as partículas do fedor suspenso naquele ambiente (TEÓFILO, 1972, p. 312).

O locus horribilis é caracterizado como um corpo infecto, em decomposição, como é explícito pelo vocabulário médico utilizado - "úlcera", "gangrena", “chaga". O narrador procura reforçar a deterioração do ambiente apelando para estímulos sensoriais, especialmente os olfativos - "cheiro de chaga", "partículas de fedor". Na sequência, Silvestre descobrirá que o "nauseabundo cheiro" pertenceria a um corpo, provavelmente morto. Movido por pura curiosidade, o cangaceiro se surpreende ao encontrar alguém vivo: "Poucos passos havia dado quando os seus olhos descobriram a figura hedionda de um homem que a fome reduzira a hiena” (TEÓFILO, 1972, p. 312). A criatura é minuciosamente descrita pelo narrador:

O monstro, que estava acordado, levantou-se. Havia na caverna bastante luz para que Silvestre visse o corpo bronzeado do caboclo inteiramente nu. A pele de engelhada parecia escamenta. As juntas dos membros pareciam nós nas extremidades de finos cilindros. Do pescoço até as nádegas estendia-se um rosário formado pelas vértebras do espinhaço. Ao tronco, cujos ossos se 


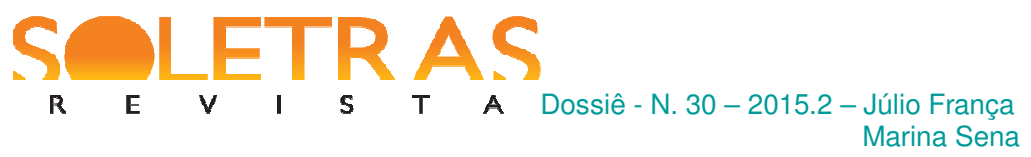

contavam todos pelas saliências das superfícies, articulavam-se magríssimos braços e pernas; por cúmulo de fealdade e complemento da horripilante figura, uma cabeça de rosto escaveirado, coberta de cabelos grossos e hirtos, coroava a múmia, balançando-se articulada em finíssimo pescoço.

Animavam o rosto daquela criatura bestificada as cintilações hidrófobas dos seus pequenos olhos, encovados em fundas órbitas. A ferocidade do olhar contrastava com o riso, que a fome havia tornado perene, atrofiando os lábios e deixando os dentes descobertos. Aquela expressão desdenhosa, motejo mudo de um esqueleto, impressionava pior do que todos os traços que a fome havia impresso no corpo do desgraçado (TEÓFILO, 1972, p. 312-213).

Este retirante já não pertence à civilização humana. Sua caracterização como "hiena" (p. 312), "criatura bestificada", cujo olhar possui "cintilações hidrófobas" (p. 313) e "ferocidade" traz os pressupostos darwinistas da condição animal do homem. A descrição anatômica é complementada por adjetivos pertencentes ao campo semântico da morbidade e da degeneração física: "horripilante figura", "múmia", "rosto escaveirado", "esqueleto". A denominação dada pelo narrador - monstro - apenas reforça o caráter incomum daquele ser. Em outras palavras, a descrição naturalista apela para um vocabulário gótico para dar expressar a profunda repulsa inspirada pela criatura.

O monstro produzido pela seca poderia ser descrito como fora, parágrafos antes, a Serra do Cajueiro: "úlcera mal cicatrizada, coberta de crosta sã, tendo sobre ela pontos podres onde fazia pasto a gangrena" (TEÓFILO, 1972, p. 312). É nesse sentido que a figura do retirante complementa o locus horribilis, funde-se com ele.

$\mathrm{Na}$ continuidade da cena, Silvestre, depois de ser atacado pelo retirante e matá-lo, entra na gruta que o mesmo habitava:

O cheiro que o nauseava era intenso. A gruta tinha um só compartimento, mas era francamente iluminada pela luz do sol que entrava por algumas fendas do teto.

Silvestre olhou o recinto; pareceu-lhe estar em um cemitério. Ossos de todos os tamanhos, cabeças humanas juncavam o chão da furna.

A um canto, sobre uma trempe de pedras, fervia uma panela de barro cheia pela boca de ossos e tendões.

Daquela panelada é que saía o cheiro da úlcera, de couro ardido. Grande foi o espanto do criminoso quando, olhando com atenção para o conteúdo da panela, viu que as peças que coziam, eram orelhas humanas a se mexerem no burburinho da fervura e no meio delas alguns peitos murchos de mulher: era a refeição do faminto (TEÓFILO, 1972, p. 314-315).

A comparação da gruta a um cemitério aponta, seguindo o tom da descrição do monstro, para um campo semântico ligado à morte e à degeneração física. A minuciosa narração de 


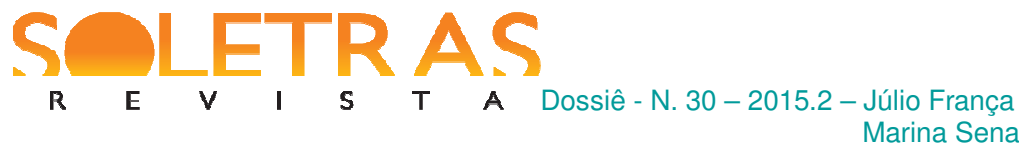

partes espalhadas de corpos descreve um espaço aterrorizante, mas o locus horribilis não é, precisamente, o local geológico - a gruta - e sim a paisagem construída pelos pedaços humanos e por suas respectivas implicações sensoriais, como "o cheiro da úlcera" (p. 315). Como aponta Borges Filho, frequentemente “(...) não é o espaço que influencia a personagem, mas o contrário: a personagem transforma o espaço em que vive, transmitindo-lhe suas características ou não" (BORGES FILHO, 2007, p. 39). Nestes termos, a influência é mútua: tanto o retirante seria transformado pela seca como ele próprio transformaria o espaço. Assim, o locus é uma extensão da personagem monstruosa que o habita, sendo tão deformado e aterrorizante como ela.

O tom mórbido da narrativa teofiliana é potencializado quando o narrador caracteriza os sertanejos como uma entidade coletiva, completamente despojados de individualidade, como no seguinte trecho em que Jesuíno observa os retirantes disputando sacos de víveres que seriam futuramente distribuídos:

Daquele elevado palanque, tinha debaixo de vista o formigar dos famintos sobre o comboio de víveres. O espetáculo, embora visto de longe, era o mesmo, triste e desolador. $\mathrm{O}$ Brilhante não podia distinguir as vértebras do esqueleto, não via o engelhamento da pele desorganizada pela miséria, via uma enorme múmia formada de centenas de criaturas bestializadas pela fome! Não lhe chegavam aos ouvidos as pragas, as imprecações, mas um zunzum surdo, um ruído em que se fundiam desde o ai até a blasfêmia.

A massa compacta, que parecia um corpo só, foi pouco a pouco se distendendo. A figura alterou-se; tomava as formas de um grande polvo. Inúmeros tentáculos moviam-se, procurando a orla da floresta.

Aqueles compridos apêndices eram formados por famintos que, tendo saciado a fome, fugiam para os covis arrastando sacas de víveres. Os que apenas tinham forças para carregar a ossada e as pelancas depois de cheio o estômago de farinha e de carne crua, não podendo nem consigo e entorpecidos como jiboia, ficavam na mais estúpida quietação. Estes formavam o corpo do molusco.

Os tentáculos se reproduziam e entravam de mata adentro, se estirando até os mais empinados penhascos (TEÓFILO, 1972, p. 282-283).

A descrição inicia-se com metáforas corporais, compostas de vocábulos científicos - "as vértebras do esqueleto", “o engelhamento da pele desorganizada pela miséria” (p. 282) -, como se o próprio conjunto de retirantes constituísse um único corpo monstruoso: "a massa compacta, que parecia um corpo só". Este corpo tem uma aparência aterrorizante - "uma enorme múmia formada de centenas de criaturas bestializadas pela fome", tal qual um gigantesco polvo que se arrastasse pela terra seca -, realizando plenamente a ideia da paisagem humana que se constitui como o locus horribilis. 


\section{Conclusão}

Foi por descrições dessa natureza que Teófilo foi acusado de excessos e de ter se afastado do projeto estético do Naturalismo. O ponto de vista que aqui defendemos, porém, é de que tais características poderiam ser melhor descritas e entendidas se lidas como o resultado de uma confluência das poéticas góticas e naturalistas.

Ao afirmarmos que a prosa de Teófilo utiliza-se de elementos característicos da estética gótica não buscamos, tampouco, afirmar que ela não seja naturalista: as duas estéticas não são opostas, muito pelo contrário, possuem diversos pontos em comum, como foi demonstrado. $\mathrm{O}$ Gótico-Naturalismo em Teófilo, como em outros de nossos naturalistas, oferecia uma forma adequada de lidar com os problemas de seu tempo e com a temática de sua prosa.

O romance Os Brilhantes exemplifica, assim, como a poética gótica interferiu no projeto Naturalista, não de maneira a negá-lo ou anulá-lo, mas de maneira a contribuir para a construção de uma prosa desencantada com o ser humano e com os rumos da modernidade, muito característica do fin-de-siècle.

\section{Referências bibliográficas:}

BORGES FILHO, Ozíris. Espaço e literatura: introdução à topoanálise. São Paulo: Ribeirão, 2007.

BOSI, Alfredo. História concisa da literatura brasileira. São Paulo: Cultrix, 2006.

BRAYNER, Sônia; COUTINHO, Afrânio. Nota Preliminar. In: TEÓFILO, Rodolfo. Os Brilhantes. Brasília: Instituto Nacional do Livro, 1972, p. 7-10.

CAMINHA, Adolfo. Cartas Literárias. Rio de Janeiro: Tipografia Aldina, 1895.

CAMPOS, José; STUDART, Ticiana. Secas no Nordeste do Brasil: origens, causas e soluções. Disponível em: <http://www.deha.ufc.br/ticiana/Arquivos/Publicacoes/Congressos/2001>. Acesso em 13 de julho de 2015.

CANDIDO, Antonio. Introdução à literatura brasileira. São Paulo: Humanitas Publicações, 1999.

CARVALHO, Aderbal de. O homem. Diário de Notícias. Rio de Janeiro, 13 de outubro de 1887.

CROW, Charles. Jack London's The Sea Wolf as Gothic Romance. In. SMITH, Allan Lloyd, org. Gothick Origins and Innovations. Amsterdam: Rodopi, 1994, p. 123-131. 
DUARTE, Urbano. O mulato. Gazeta da Tarde. Rio de Janeiro, 08 de julho de 1881.

FRANÇA, Julio. As sombras do real: a visão de mundo gótica e as poéticas realistas. In.: CHIARA, Ana; ROCHA, Fátima Cristina Dias, org. Literatura Brasileira em Foco VI: em torno dos realismos. Rio de Janeiro: Casa Doze, 2015, p. 133-146.

MENDES, Leonardo. Júlio Ribeiro, o Naturalismo e a dessacralização da literatura. Pensares em Revista. São Gonçalo, RJ: Universidade do Estado do Rio de Janeiro, n. 4, p. 26-42, jan.jul. 2014.

As ruínas da homossexualidade: o gótico em Bom-Crioulo, de Adolfo Caminha. Luso-Brazilian Review. Madison: University of Wisconsin (EUA), vol. 41, n. 1, p. 56-70, 2004.

MENON, Maurício César. Figurações do gótico e de seus desmembramentos na literatura brasileira de 1843 a 1932. Londrina: UEL, 2007.

PEREIRA, Lúcia Miguel. História da literatura brasileira: prosa de ficção, de 1870 a 1920. São Paulo: Editora da Universidade de São Paulo, 1988.

PRADO, Antonio Arnoni. Aluísio Azevedo e a crítica. In: AZEVEDO, Aluísio. Ficção completa. Rio de Janeiro: Nova Aguilar, 2005, p. 43-54.

ROMERO, Sílvio. O naturalismo em literatura. São Paulo: Tipografia da Província de São Paulo, 1882.

ROQUE, José Sebastião. Vida e obra de Cesare Lombroso. In: LOMBROSO, Cesare. $O$ Homem Deliquente. São Paulo: Ícone, 2007, p. 5-12.

SODRÉ. Nelson Werneck. O Naturalismo no Brasil. Rio de Janeiro: Civilização Brasileira, 1965. São Paulo: Ícone, 2010.

STEVENS, David. The Gothic tradition. Cambridge: Cambridge University Press, 2000.

SÜSSEKIND, Flora. Tal Brasil, qual romance?. Rio de Janeiro: Achiamé, 1984.

TEÓFILO, Rodolfo. Os Brilhantes. Brasília: Instituto Nacional do Livro, 1972.

TUAN, Yi-fu. Paisagens do medo. São Paulo: UNESP, 2005.

VERÍSSIMO, José. Estudos de Literatura Brasileira: primeira série. Rio de Janeiro: Tipografia Garnier, 1901.

História da Literatura Brasileira: de Bento Teixeira (1601) a Machado de Assis (1908). Rio de Janeiro: Topbooks, 1998. 


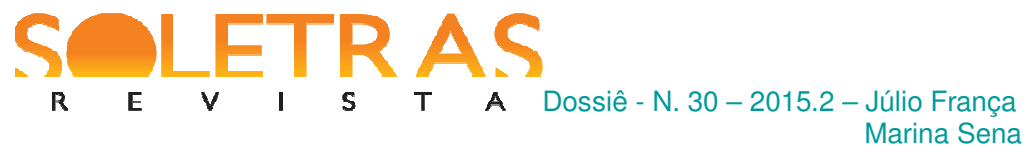

\section{Gothic-Naturalim in Rodolfo Teófilo}

Abstract: Rodolfo Teófilo (1863-1932), the so-called master of Naturalism in Ceará, focused his fictional works on the nineteenth-century dreadful environment of drought and famine in the Northeast of Brazil. Most of Teófilo's stories (especially the ones written between 1877 and 1879) are set in the sertão ravaged by drought. His fictional loci, in turn, stand out for being frightful, scanty, and desolated. Struggling to survive in such a space, Teófilo's characters are individuals who experience the horrors of famine. As a result, little by little they are transformed into subhuman, animalistic, and instinctive creatures - until they lose touch with humanity altogether. Strongly scientific-centered, the naturalist novelist describes the morbid and sexual scenes so vividly to the point of being accused (by his contemporary critics and nineteenth-century historiographers) of having built up "excessive descriptions" as well as of having committed fictional excesses. Regarding these points, we aim at analyzing Rodolfo Teófilo's novel Os Brilhantes (1985) in order to show that these exaggerations claimed by critics may be related to the Gothic style. We believe that there is an aesthetic confluence of the Gothic and Naturalism in Teófilo's narrative, which may explain such exaggerations.

Keywords: Naturalism. Gothic. Rodolfo Teófilo.

Recebido em: 30 de setembro de 2015 .

Aprovado em: 12 de novembro de 2015. 